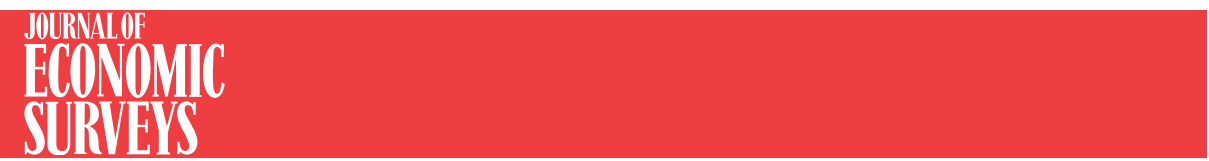

doi: $10.1111 /$ joes. 12247

\title{
LINGUISTIC STRUCTURES AND ECONOMIC OUTCOMES
}

\author{
Astghik Mavisakalyan* (iD) \\ Curtin University \\ Clas Weber \\ University of Western Australia
}

\begin{abstract}
Linguistic structures have recently started to attract attention from economists as determinants of economic phenomena. This paper provides the first comprehensive review of this nascent literature and its achievements so far. First, we explore the complex connections between language, culture, thought and behaviour. Then, we summarize the empirical evidence on the relationship between linguistic structures and economic and social outcomes. We follow up with a discussion of data, empirical design and identification. The paper concludes by discussing implications for future research and policy.
\end{abstract}

Keywords. Culture; Economic behaviour; Language; Linguistic structures

\section{Introduction}

Language has received renewed interest in economics in recent years. In part, this is because, quite generally, awareness of cultural factors as possible determinants of economic outcomes has increased considerably (e.g. Guiso et al., 2006; Fernandez, 2008; Alesina and Giuliano, 2015). Another, more intriguing reason is that the structure of our language may influence our thinking, which in turn affects our behaviour. There is now a growing body of literature in economics that studies the connection between various linguistic structures and economic and social outcomes. This literature has already significantly increased our understanding of the determinants of a wide range of outcomes including savings, health, education and gender gaps. In this paper, we provide the first comprehensive overview of this exciting new literature.

There are around 7000 languages in the world and they all differ from each other in multifarious ways (Simons and Fennig, 2017). For instance, unlike English, Japanese has at least seven different second-person pronouns, indicating different levels of politeness. The common explanation is that this linguistic difference reflects differences in underlying culture and social structure. But languages may in turn influence culture by shaping the form and content of the cultural information that is being passed on from generation to generation. And they can also sustain or amplify cultural influences by giving them a robust and lasting manifestation (Galor et al., 2016). Finally, there is evidence that language may have a direct effect on cognition and thus on behaviour.

*Corresponding author contact email: astghik.mavisakalyan@curtin.edu.au; Tel: +61 892664412. 
That language has a systematic influence on thought is the central idea behind the so-called Linguistic Relativity Hypothesis (LRH). While there are numerous studies on the effects of linguistic structures in linguistics and psychology, as hypothesised by the LRH (for overviews, see, e.g. Lucy, 1997; Boroditsky, 2003; Casasanto, 2015), the studies in economics differ from these both in the way they are done and in the phenomena they investigate. They typically use much larger sample sizes and they study the connection between linguistic structures and robust economic and social outcomes; many previous studies in linguistics and psychology use relatively small sample sizes and concentrate on smaller scale cognitive effects (e.g. slight differences in reaction times Kay and Regier, 2006).

Language is a key element of an individual's cultural endowment, and as such, the study of language is closely related to the literature on economics of culture. This literature has so far offered three main approaches to measuring culture. The most common one is through survey questions on selfreported preferences and beliefs (e.g. Alesina et al., 2013; Gorodnichenko and Roland, 2017). The second approach links the outcomes of second-generation immigrants in the same destination country to those observed in their countries of ancestry (e.g. Fernandez and Fogli, 2006, 2009). The third approach collects experimental evidence on differences in behaviours of people from different cultures (e.g. Henrich et al., 2001; Pascual-Ezama et al., 2015). The literature reviewed here serves to take the literature on the economics of culture beyond its focus on these approaches to measurement. Studying linguistic factors is attractive from a methodological viewpoint as the variables studied by linguistics are clearly defined, well understood, and relatively easy to measure. Analyses of linguistic structures reviewed in this paper is one significant case of such application. ${ }^{1}$

The cognitive-behavioural effect of linguistic structures is different from the effect of language skills commonly studied in economics. The origins of the economics of language are often linked to the work of Jacob Marschak (1965), who was interested in efficiency of communication. Traditionally, language skills are considered a form of 'human capital' since they are embodied in a person, productive in the labour market and obtained at the cost of time, effort and out-of pocket expenses (e.g. Chiswick and Miller, 2015). Accordingly, there are positive returns to language skills, particularly in the labour market (recent contributions include Di Paolo and Tansel, 2015; Duncan and Mavisakalyan, 2015; Yao and van Ours, 2015, among many others). Economic returns to language proficiency are also observed at the aggregate level: languages foster bilateral trade (e.g. Melitz, 2008; Fidrmuc and Fidrmuc, 2016). However, for each language the reason why its possession has productive value is the same: it enhances efficiency in communication (in the respective context) (Lazear, 1999). In contrast, many languages differ in interesting ways in their effects on cognition and behaviour. For example, speaking English has productive value in an English speaking country, just as speaking German does in a German speaking country. However, the two languages differ in the way they encode reference to the future, and this fact seems to have a substantial effect on its speakers' cognition and many economic and social outcomes (Chen, 2013). Hence, the insights from studies on the effects of linguistic structures suggest that the influences of language extends far beyond its traditional role, opening up exciting new avenues for economics.

In this paper, we first provide some background on the relationship between culture, language, cognition and behaviour, and lay out potential ways of conceptualizing the effect of linguistic structures on decision making (Section 2). Then, in Section 3, we summarize the existing empirical evidence in the economics literature, focusing on the four linguistic structures studied so far: grammatical gender, tense, personal pronouns and mood. Following the summary of the literature, Section 4 describes the sources of data and discusses issues of measurement in studies of economic and social effects of linguistic structures. Section 5 points out the key challenge the field needs to address: that of establishing causality. We consider in detail different proposals of how to deal with the issue of unobserved heterogeneity in studying the economic effects of linguistic structures. We conclude with a discussion of directions for future research and policy implications in Section 6. 


\section{Conceptual Background}

\subsection{Language and Culture}

Culture and language are connected in complex ways. On the one hand, many features of language are reflections of culture; for instance, Levinson (2003, p. 27) writes, 'The contents of language, and much of its form, are [...] largely the products of cultural tradition [...]'. On the other hand, language is the dominant medium through which culture is transmitted. Language may therefore have a formative influence on the shape and character of the cultural information passed on from one generation to the next. Further, once cultural traits have found a linguistic manifestation, they may become more rigid and less susceptible to change (Tabellini, 2008; Galor et al., 2016). They may take on 'a life of their own' and sustain or amplify the influence of culture or facilitate its diffusion (Galor et al., 2016). In the following, we will give explicit characterizations of linguistic structures and culture and sketch some of the important connections between language, culture, thought and behaviour.

Languages can be characterized in terms of a set of basic linguistic features and a set of combinatorial rules, specifying which combination of basic features are admissible (Chierchia, 1999). Linguistic features and their corresponding combinatorial rules fall into several main categories: syntax (including the lexicon), morphology/semantics and phonology. For instance, the syntax of a language specifies its basic syntactic features, for example, subject, object, verb (or rather, noun phrase, verb phrase, etc.), and the manner in which they can be combined (i.e. the corresponding combinatorial rules). Some languages admit only combinations of the form subject-object-verb as grammatically well-formed sentences, others allow combinations of the form verb-subject-object. Linguistic structures are complexes of linguistic features and combinatorial rules-different linguistic structures differ either in their basic linguistic features or their combinatorial rules. Ultimately, what explains the effect of language on an individual's cognition and behaviour is the fact that the individual speaks a language that instantiates a specific linguistic structure with particular linguistic features and combinatorial rules; this is what we mean when we speak of 'the effect of linguistic structures'.

Our definition of culture follows the dominant strands in economics which understand culture in terms of socially transmitted beliefs and values. ${ }^{2}$ For instance, Guiso et al. (2006, p. 23) define culture as 'those customary beliefs and values that ethnic, religious, and social groups transmit fairly unchanged from generation to generation'. Our own working assumption is that culture encompasses socially transmitted beliefs or values that are prevalent within a group, relatively stable, not empirically discovered or analytically true, and concern the interaction with others inside or outside the group and religious entities. ${ }^{3}$ Important examples of cultural beliefs/values in the economics literature are attitudes concerning trust, family, work, morality and individualism (Guiso et al., 2006; Fernandez, 2008; Tabellini, 2008; Alesina and Giuliano, 2015).

Figure 1 depicts alternative representations of the causal relationship between language, culture, cognition and behaviour. Figure 1(a) represents language as a causally inert manifestation of culture, without influence on cognition and behaviour; Figure 1(b) represents the more complex interplay between language and culture and allows for the influence of language on cognition and behaviour, that is, the central tenet of the LRH. Here, we follow the decision-theoretic paradigm, which maintains that individual behaviour is in general determined by agents' beliefs and preferences (understood in a wide sense) (Savage, 1954; Jeffrey, 1965). This means that any causal influence of culture or language on behaviour is mediated through the agent's cognitive system. ${ }^{4}$

The simple picture maintains that the language of a specific group is largely a reflection of its culture. Culture in turn influences behaviour through the channel of cognition by affecting the prevalence of certain beliefs and values/preferences within a group and thereby its members' actions.

However, it seems that the relevant causal nexus is in fact more complex. As alluded to above, language itself seems to have an influence on culture by (i) shaping the content and the form of cultural beliefs 


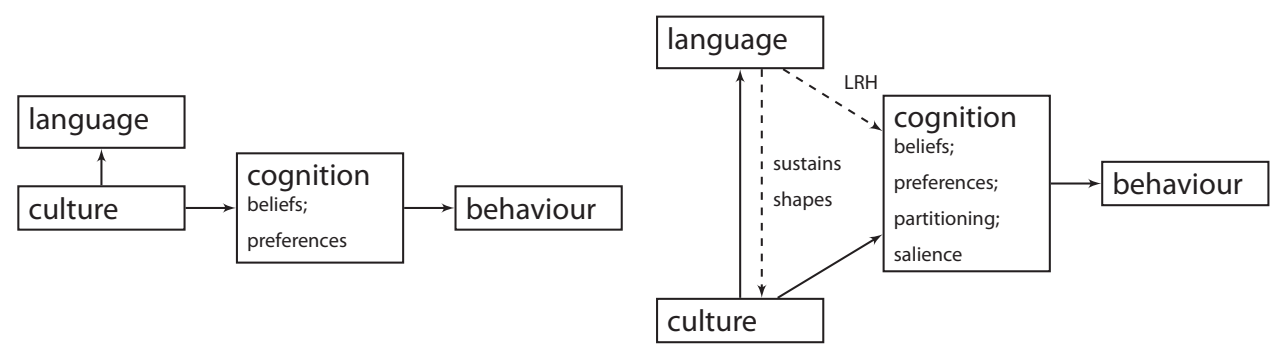

(a) The simple picture

(b) The complex picture

Figure 1. Language, Culture and Behaviour

and values; (ii) contributing to the preservation of relevant beliefs or values; (iii) amplifying the effect of culture and (iv) facilitating the diffusion of culture. It has these effects on culture through shaping thought (LRH), through being the central medium of cultural transmission, and through being more resistant to change than typical cultural beliefs and values.

Next, we will more closely consider the specific channel through which language influences cognition and behaviour as postulated by the LRH.

\subsection{The LRH}

The LRH combines a linguistic and a psychological claim: (1) languages differ in interesting ways (linguistic claim); (2) these differences affect our thinking and behaviour (psychological claim). Put in our terminology, the hypothesis states that different languages instantiate different linguistic structures and that differences in linguistic structures may have a systematic influence on the cognition and behaviour of their speakers. The hypothesis has a long and controversial history, tracing back at least to German Romanticism of the late 18th and early 19th century, in particular to Wilhelm von Humboldt. ${ }^{5}$ In the 20th century, the LRH gained influence in America, culminating in the works of the linguists Edward Sapir (1929) and Benjamin L. Whorf (1956); it is therefore also referred to as the 'Sapir-Whorf hypothesis' or simply 'Whorfism'. Whorf stated that our view of the world is fundamentally shaped by our language: '...the world is presented in a kaleidoscope flux of impressions which has to be organized by our mindsand this means largely by the linguistic systems of our minds' (Whorf, 1956, p. 213). Not long after Whorf advocated the LRH, it fell into disrepute, mainly through the rise of cognitive science, and remained unpopular until the early 1990s, both for empirical and conceptual-theoretical reasons (e.g. Pinker, 1994). First, initial claims of alleged cognitive effects of language were not borne out empirically. In addition, many early empirical studies suffered from poor experimental design and other methodological problems, for example, lack of suitable control conditions (see Takano, 1989; Lucy, 1992, 1996b). Second, the LRH faced a number of conceptual-theoretical challenges (Pinker, 1994). For instance, there was no agreed upon and precise formulation of the thesis; further, it was thought to be threatened by circularity: researchers have to assess the effect of language on thought through the medium of language itself, that is, by assessing the linguistic reports of participants (Gleitman and Papafragou, 2013). More significantly, both the rising theoretical linguistics and cognitive sciences, inspired in large part by the seminal work of Noam Chomsky, with their emphasis on innate and universally shared features of language and cognition, were perceived as in conflict with the LRH, which was itself inspired by a focus on linguistic variation and diversity (Gumperz and Levinson, 1996). 
However, starting in the mid 1990s, the LRH has experienced a revival, addressing both lines of criticism. Empirically, there are now numerous studies in linguistic and psychology which attest to the validity of the LRH; these studies have also overcome the methodological flaws of earlier attempts, for example, they include appropriate controls groups (e.g. Lucy, 1996a; Boroditsky et al., 2003; Gentner and Goldin-Meadow, 2003; Oh, 2003; Slobin, 2003; Kay and Regier, 2006; Levinson and Wilkins, 2006; Winawer et al., 2007). And, there has also been considerable conceptual-theoretical progress (e.g. Gumperz and Levinson, 1996; Casasanto, 2016). Improved and more precise formulation of the LRH are now available and it has become clear that, rightly understood, the LRH is not in conflict with Chomsky's programme.

One can distinguish general from specific versions of the LRH, as well as strong from weak ones (Scholz et al., 2016). A general version of the LRH says that there are some linguistic features which systematically influence certain aspect of thought (without taking a stance on which ones). A specific version makes a claim about particular linguistic and cognitive features, for example, that the inventory of basic colour concepts (i.e. the lexicon) has an influence on speakers' perception of colour (Kay and Regier, 2006; Winawer et al., 2007). Demonstrating that a specific version of the LRH is false does not automatically show that the more general claim is also untrue. But conversely, showing that a specific version of the LRH holds does entail the more general claim. Strong interpretations of the LRH state that language determines thought; that is, no thought (of a certain kind) without corresponding linguistic structures. Moderate readings (which we are presupposing here) merely claim that language influences thought in systematic and non-trivial ways; that is, speakers of different languages may exhibit interesting and regular cognitive differences. While strong versions of the LRH remain controversial, there is good evidence that the weaker claim is true. ${ }^{6}$

Finally, it is important to point out that a moderate interpretation of the LRH is compatible with the influential universalist approach to language, championed by Noam Chomsky (1957) and, more generally, a nativist understanding of the mind (Fodor, 1983). ${ }^{7}$ Nativists believe that important parts of our cognitive endowment are innate and biologically determined, rather than acquired through experience and learning, as empiricists maintain. The fact that important elements of our cognitive/linguistic capacities are biologically determined is consistent with the claim that different languages impose different restrictions on our innate cognitive endowment (Kay and Regier, 2006; Scholz et al., 2016). ${ }^{8}$ As pointed out above, the thought that there is a conflict between nativism and the LRH has formed the main conceptual-theoretical reason to resist the LRH. In light of both the empirical and the conceptual-theoretical advances, it seems legitimate to assume that there is a plausible and well-supported moderate interpretation of the LRH, compatible with the dominant strands in cognitive science and linguistics.

\subsection{Culture, Language and Behaviour}

Our thoughts determine our actions. By their influence on thought, both culture and language have an effect on behaviour. In this section, we sketch how one may represent both influences in a decisiontheoretic framework. The effect of culture, as defined above, seems to fit squarely into the framework. The effect of language as hypothesized by the LRH, on the other hand, seems to require a mild extension.

Decision theory answers decision problems of the following form: an agent chooses among a set of actions which have various outcomes depending on different states of the world; the agent has varying credences in different states, represented by a probability function, and desires different outcomes to varying extent, measured by a utility function. ${ }^{9}$ We follow Jeffrey (1965) in understanding actions, outcomes, and states as propositions, that is, subsets of an underlying possibility space $\Omega$. The set of actions $A$, states $S$, and outcomes $O$ form partitions of $\Omega$.

There are several pathways for linguistic and cultural factors to influence an agent's decision making. Both culture and language influence 
(1) the agent's probability function

(2) the agent's utility function

We have explained culture in terms of socially transmitted beliefs and values. An agent's beliefs are captured by a corresponding (1) probability function, while his/her values can be modelled by an appropriate (2) utility function. The effect of culture therefore can be straightforwardly accommodated within the standard paradigm. ${ }^{10}$ While the effect of language likewise occurs through these two channels, it can influence behaviour also through:

(3) the grain in which $A, S, O$ partition $\Omega$

(4) the salience of elements of $A, S, O^{11}$

We will now characterize the specific influence of language along all four dimensions.

(1) Probability function: Different languages may have a systematic effect on the information its speakers possess. For instance, certain Australian languages comprise only absolute spatial terms (e.g. such as north, south) and no relative ones (such as right, left) (Levinson and Wilkins, 2006). Speakers of these languages constantly keep track of their absolute orientation in space, assigning higher credence to statements like that tree is to the north than do speakers of other languages. It has also been shown that our probability judgments are influenced by cognitive availability, that is, 'the ease with which instances can be brought to mind' (Tversky and Kahneman, 1975, p. 1127). Availability in turn is influenced by language through its effect on, for example, attention, memory, perception, verbalization and recognition.

(2) Utility function: Language may affect our preferences. For instance, Chen (2013) argues that speakers of languages with future tense are more prone to discount future rewards. Further, Givati and Troiano (2012) and Mavisakalyan (2015) find evidence that grammatical gender affects preference structure and reinforces discriminatory gender attitudes, for example, speakers of gendered languages are more likely to support preferential hiring of men. Other linguistic features that seem to fall into this category are pronoun drop affecting pro-social preferences (Kashima and Kashima, 1998); pronoun politeness distinctions influencing attitudes concerning social hierarchy (Kashima and Kashima, 1998; Davis and Abdurazokzoda, 2016); use of agentive versus non-agentive verbs modifying evaluative attitudes about blame and punishment (Fausey and Boroditsky, 2010, 2011) and subjunctive mood influencing risk aversion (Kovacic et al., 2016).

(3) Grain of partitioning: How agents represent different states of the world, their options and outcomes depends on what kind of distinctions they are able to draw, that is, on their conceptual resources. The richer an agent's conceptual repertoire, the more distinctions she can make, the finer she can partition $\Omega$. This may affect her decision making, since not all partitionings are equal - appropriate partitionings are sensitive to the agent's utility and probability function (Bradley, 2017, p. 12). For example, in deciding whether to take an umbrella an agent has to consider the probability of rain and the cost of getting wet. Hence, an appropriate partition of $\Omega$ divides states in a way that distinguishes between rain and absence of rain and outcomes such that they differ between her staying dry and her getting wet. Linguistic features that influence grain of partitioning are related to conceptual structure, that is, to how we categorize the world. One such example is grammatical gender. When choosing between two job candidates, agents that speak a gendered language may often represent their choice accordingly: Shall I choose him or her? While speakers of gender-neutral languages may conceptualize the decision in a way that does not so distinguish: Shall I choose this person or that person? This can matter in case the agent's probability or utility function are sensitive to this contrast, for example, if she assigns high credence to men are better at the job than women (Mavisakalyan, 2015; Perez and Tavits, 2016). Other linguistic features in this category are, for 
example, tense, spatial concepts, number words and colour terms (e.g. Levinson and Wilkins, 2006; Casasanto and Boroditsky, 2008; Frank et al., 2008; Regier and Kay, 2009; Casasanto, 2010). ${ }^{12}$

(4) Salience: Language may highlight certain actions, outcomes or states. This effect can potentially be distinct from the ones considered before. First, two languages may divide $\Omega$ into the same cells (see (3)), but still differ in which cells are made salient. Second, while this may typically influence an agent's probability or utility function (see (1) and (2)), it does not need to do so; an agent may choose a certain option over its alternatives not because language has raised its expected utility, but rather because language has placed it at the centre of her attention. This is especially significant for nonideal, boundedly rational agents, such as ourselves, who cannot consider each and every possible option or consequence, but are confined to decide between a limited subclass thereof. Language may affect salience, for example, by which distinctions are syntactically encoded, for example, grammatical gender (Mavisakalyan, 2015), tense (Chen, 2013), which are lexically encoded, for example, colour terms (Kay and Regier, 2006), or which are emphasized by being regularly used, for example, agentive versus non-agentive verbs (Fausey and Boroditsky, 2011). ${ }^{13}$

The above is not intended as a comprehensive classification of mechanisms or linguistic features. It is meant to facilitate the understanding and structuring of the evidence on the influence of linguistic structures presented in the next section.

\section{Existing Evidence}

There is a small, yet rapidly growing literature on the relationship between linguistic structures and economic behaviour (Table 1 presents a summary of the main contributions to this literature discussed here.). Earlier studies explicitly treat linguistic structures as a source of exogenous variation in culture, and on that basis, exploit the relevant linguistic variables for identifying the effect of cultural preferences and beliefs on socioeconomic outcomes (e.g. Licht et al., 2007; Tabellini, 2008). The majority of more recent studies focuses on the socioeconomic effects of linguistic structures themselves. In many of these studies, linguistic structures are largely construed as proxies for culture (e.g. Santacreu-Vasut et al., 2014; Bhalotra et al., 2015). Others allow for the possibility that linguistic structures may affect outcomes via cultural as well as cognitive channels without empirically distinguishing between the two (e.g. SantacreuVasut et al., 2013; Hicks et al., 2015). Yet, a third group of studies aspires to explore whether linguistic structures might influence behaviour by directly altering a speaker's cognition consistent with the LRH (e.g. Chen, 2013; Mavisakalyan, 2015).

The literature is based on comparisons both between countries as well as between individuals within linguistically heterogenous countries. So far, existing studies have focused on evaluating the outcomes of four types of linguistic features: (i) gender, (ii) tense, (iii) personal pronouns and (iv) mood. In what follows, we summarize the existing evidence on the economic effects of linguistic structures resulting from this literature.

\subsection{Impact of Gender}

Languages differ in whether or not they require speakers to grammatically mark gender. As Corbett (2013a) notes, gender systems 'pervade some languages, are of some importance in others, and are missing in yet others'. The need to make reference to gender in language may influence individuals' credences, their preferences, the distinctions they draw and their salience (see Section 2.3). In particular, it appears to raise the significance of traditional gender roles in the mind of the speaker. This impacts on gender role distinctions and gender bias in societies. For this reason, feminists have criticized the use of grammatical gender marking as contributing to gender inequalities, see Saul (2012) for an overview of 


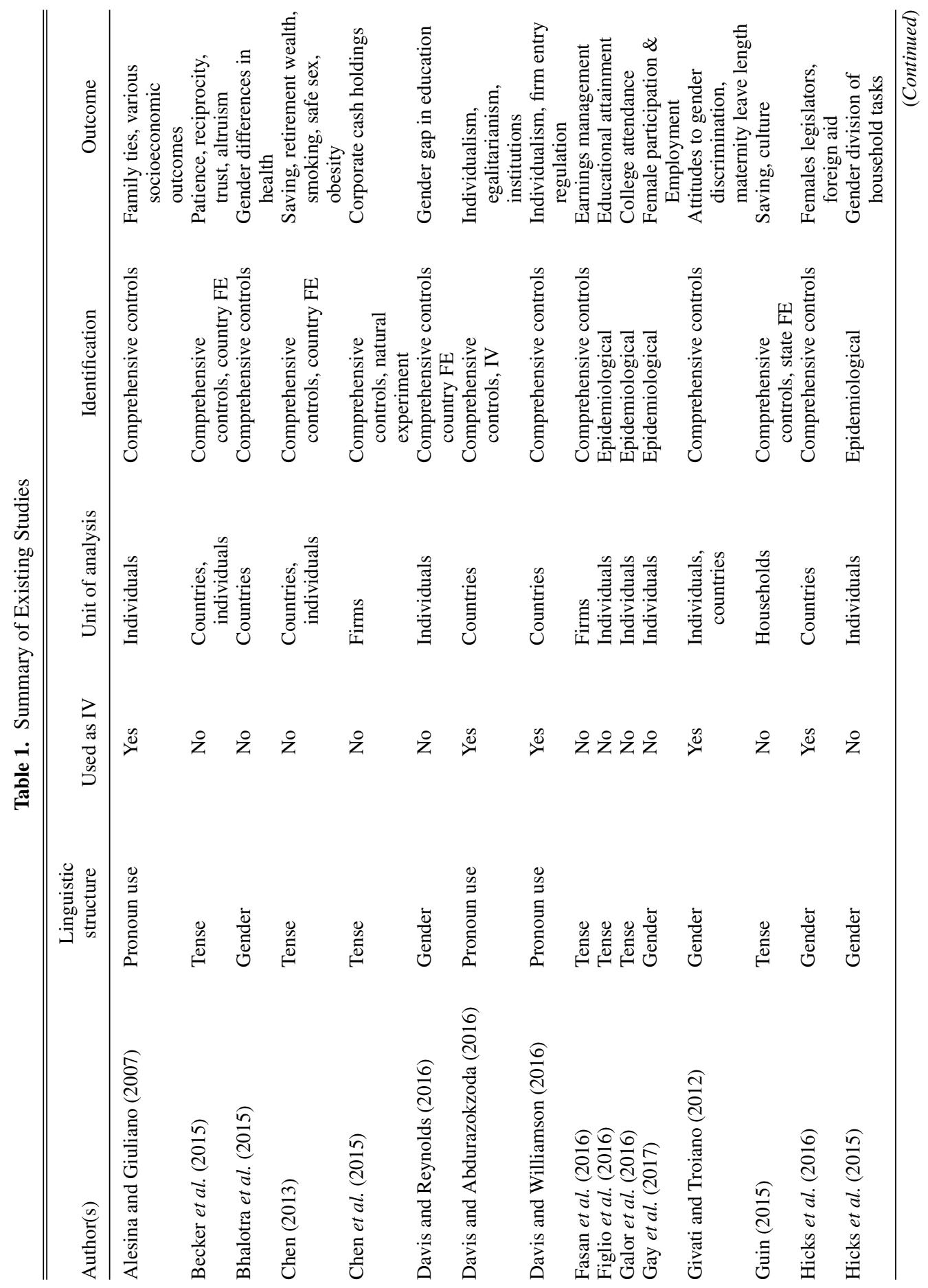


this literature. A number of recent studies investigate the implications of variation in grammatical gender marking for women's outcomes.

For a linguist 'gender' does not simply refer to the colloquial distinction between men and women. Formally, a language possesses a gender system if it has classes of nouns which require inflectional agreement with other elements in the sentence (e.g. Corbett, 1991). Some languages, like Finnish, make no distinctions between noun classes, others, like Thai, distinguish between almost 20 different ones. The contrast between grammatical and natural/semantic gender can be illustrated by the German construction 'das Fräulein' (the Miss). Grammatically, the noun 'Fräulein' is of neuter gender, requiring agreement with the neutral article 'das', while its natural/semantic gender is female, as it refers to a woman.

The contrast between grammatical and natural gender gives rise to a challenge. So far, there are two approaches to address this challenge. The first acknowledges that grammatical gender doesn't always track underlying differences in biological sex; indeed, less than half of the 112 language in the World Atlas of Language Structures (WALS) base their assignment of nouns into genders on semantical distinctions (Corbett, 2013b). A promising proposal is to focus on personal pronouns systems (e.g. he vs. she in English), where gender assignment does indeed track underlying biological distinctions (e.g. Givati and Troiano, 2012; Mavisakalyan, 2015). The second approach is to simply utilise all available measures of grammatical gender from cross-linguistic sources such as WALS, remaining largely ambiguous on their relevance to the study of sex-based socio-economic inequalities (e.g. Santacreu-Vasut et al., 2013; Hicks et al., 2015). These include (i) the number of genders, that is, the number of noun types requiring agreement; (ii) whether the gender system is sex based; (iii) systems of gender assignment (semantic vs. formal) and (iv) gender distinctions in personal pronouns, used independently or in various combinations.

There is growing evidence that grammatical gender is associated with gender inequalities at work and in the household. It is linked to lower female labour force participation and hours worked across countries and individuals (e.g. Mavisakalyan, 2015; Gay et al., 2017). Further, grammatical gender appears to have negative implications specifically for female participation on corporate boards and senior management positions (Santacreu-Vasut et al., 2014). It is not surprising then that having a gendered language is associated with larger estimates of gender wage gaps across countries (van der Velde et al., 2015). There are also consequences for gender inequalities inside the household, leading to a gendered division of labour in household tasks (Hicks et al., 2015).

How does grammatical gender influence women's outcomes? One plausible mechanism is investment in human capital. Davis and Reynolds (2016) give evidence that speaking a gendered language increases the educational gender gap within countries. Furthermore, recent evidence suggests that it is correlated with gender inequalities in health. Bhalotra et al. (2015) show increases in maternal mortality rates and reductions in the female advantage in life expectancy across countries. Another channel may be its effect on institutions. The literature suggests a connection between gendered languages and an absence of institutions promoting gender equality. Givati and Troiano (2012) show that speaking a gendered language is negatively correlated with the length of maternity leave across countries. Santacreu-Vasut et al. (2013) present evidence that it is negatively associated with the adoption of political gender quotas, and also affects the efficacy of such quotas (Santacreu-Vasut et al., 2013; Hicks et al., 2016). Most significantly perhaps, grammatical gender has an influence on gender-discriminatory attitudes. Givati and Troiano (2012) and Mavisakalyan (2015), for example, show that speakers of gendered languages are more likely to express support for giving men preferential access to jobs; Perez and Tavits (2016) document a negative effect on support for policies to combat gender imbalances.

\subsection{Impact of Tense}

Another linguistic feature that has received significant attention from economists is future tense. Languages encode reference to future events in different ways. Some, such as German, use the present tense to talk 
about future events. Others, such as English, make use of auxiliary verbs (shall/will), or, like French, use a dedicated future tense form.

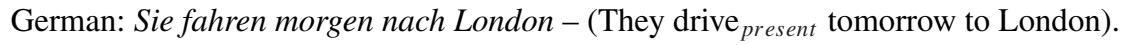

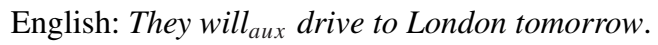

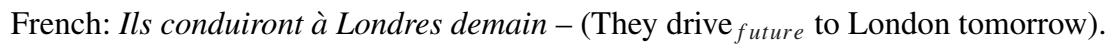

We can then distinguish languages that do not require future tense marking, that is, weak FTR languages such as German, from languages that necessitate some form of future tense marking, that is, strong FTR languages such as English and French (Chen, 2013). ${ }^{14}$

Future tense marking seems to have an influence on speakers' intertemporal choices. In a seminal paper, Chen (2013) formulates a 'linguistic-savings hypothesis': being required to speak in a distinct way about future events leads speakers to take fewer future-oriented actions. One explanation proposed by Chen (2013) is that future tense marking subjectively projects future events further away from the speaker's present. As a result, speakers of such languages have a stronger tendency to discount future rewards. Several variations of this hypothesis have been formulated and tested in recent studies.

In his study Chen (2013) shows that speakers of weak-FTR languages save more, retire with more wealth, smoke less, practice safer sex and are less obese. This evidence holds across countries as well as within linguistically heterogenous countries. The linguistic-savings hypothesis is confirmed in studies of household saving behaviour by Guin (2015) and Paule-Paludkiewicz et al. (2016). Tense marking can also affect educational attainment; Figlio et al. (2016) show that speakers of weak-FTR languages perform better in third-grade reading and math tests, have larger test score gains over time and fewer absences and disciplinary incidents, are less likely to repeat grades and more likely to graduate from high school within four years. Furthermore, they are more likely to attend college (Galor et al., 2016).

These effects also carry over to behaviour at the corporate level. Recent evidence suggests that firms in weak-FTR language locations perform better at corporate social responsibility practices (Liang et al., 2014), have higher precautionary cash holdings (Chen et al., 2015), engage less in earnings management (Fasan et al., 2016) and invest more in research and development (Su et al., 2016). Interestingly, a study by Liang et al. (2014) finds that the link between linguistic FTR and a firm's future-oriented activities is weaker for firms with greater exposure to diverse global languages through being headquartered in countries with higher degree of globalization, having a higher degree of internationalization and having a CEO with more international experience.

Further studies document that intertemporal preferences might indeed be an important mechanism mediating the effect of future tense. Sutter et al. (2015) demonstrate strong differences in the intertemporal choices of children speaking strong- and weak-FTR languages in a controlled experiment. Hübner and Vannoorenberghe $(2015 \mathrm{a}, \mathrm{b})$ exploit differences in future tense marking across countries to identify the effect of different time preference measures on macroeconomic outcomes, such as income per worker, total factor productivity, the capital stock and inflation. Moreover, in a recent globally representative assessment of distribution and nature of behaviourally validated survey measures of preferences, Becker et al. (2015) show that the predictive power of FTR is not limited to time preference. As this study demonstrates, weak FTR is also associated with higher levels of prosocial traits such as positive reciprocity, altruism and trust across countries. Although not explored in the study, these preferences should have influence over a range of important aggregate outcomes.

\subsection{Impact of Pronoun Use}

Grammatical rules governing personal pronouns have also recently been investigated in economics, largely building on the social psychology study by Kashima and Kashima (1998). Two aspects of pronoun use are considered: pronoun drop and politeness distinctions in pronouns. 
In some languages. pronouns can be omitted in their position as grammatical subject. For instance, Spanish permits both 'Yo estoy cantando' and simply 'Estoy cantando' for the English I am singing. In the second sentence, the pronoun 'Yo' has been dropped. This distinction seems to have implications for the contrast between cultural individualism versus collectivism. As Kashima and Kashima (1998) note, 'An explicit use of 'I' signals that the person is highlighted as a figure against the speech context that constitutes the ground; its absence reduces the prominence of the speaker's person, thus reducing figureground differentiation' (p. 465). Non-pronoun drop languages are expected to be associated with more individualist cultures, while pronoun drop languages are expected to be associated with more collectivist cultures.

A different aspect of personal interactions is linked to politeness distinctions in second-person pronouns (you). In some languages (e.g. German, Spanish) there are two different singular second-person pronouns (e.g. du, Sie) to index social distance in interactions. In other languages (e.g. English) no such distinction exists and only a single second-person pronoun singular is used regardless of the social distance between speakers. According to Kashima and Kashima (1998), speakers of languages with multiple yous are more conscious of status or social distances than the speakers of other languages. Therefore, the politeness distinction in personal pronouns is expected to bear implications for cultural norms associated with hierarchy and egalitarianism.

Existing studies on the effects of grammatical rules of personal pronouns use have been largely based on the data from Kashima and Kashima (1998, 2005). Accordingly, variables for pronoun drop and the number of second-person singular pronouns available in a language have been employed. A recent study by Davis and Abdurazokzoda (2016) provides new data on these variables based on more refined linguistic information. The studies document a significant relationship between pronoun drop and individualism across societies, however the relationship between politeness distinctions and indicators of culture is less robust (Kashima and Kashima, 1998; Davis and Abdurazokzoda, 2016).

The work by Kashima and Kashima $(1998,2005)$ has motivated using personal pronouns as instruments for key dimensions of culture such as individualism versus collectivism and egalitarianism versus hierarchy in studies of their effects on economic outcomes. Cross-country studies by Licht et al. (2007) and Tabellini (2008) provide the initial contributions to this literature, using linguistic variables to identify the causal relationship between culture and institutions. Using pronoun drop as an instrument for cultural emphasis on 'autonomy' versus 'embeddedness', Licht et al. (2007) find a significant influence of culture on the rule of law, corruption and democratic accountability. They do not consider politeness distinctions in pronouns in their identification approach. Taking a similar approach to identification, Alesina and Giuliano (2007) study the effect of cultural attitudes towards the family on a range of economic and social outcomes across countries. A study by Tabellini (2008) exploits a composite linguistic variable incorporating both pronoun drop and politeness form differentiation as an instrument to study the link between the culture of 'generalized' versus 'limited' morality in a society (whether norms of good conduct apply towards everybody or just in a narrow group with which the individuals identify) and the quality of government. Davis and Abdurazokzoda (2016) replicate the results in Licht et al. (2007) and Tabellini (2008) using new linguistic data on personal pronoun use. Another recent study by Davis and Williamson (2016) uses pronoun drop rule as an instrument to demonstrate a causal link between individualistic cultures and a country's propensity to regulate the entry of new firms.

\subsection{Impact of Moods}

Finally, economists have studied the grammatical feature of mood. There are two general classes of mood: realis and irrealis. Roughly, the mood of a verb differentiates factual from hypothetical statements. For example, 'John is taking ${ }_{i n d}$ an aspirin' is in the indicative mood, signalling that it is a statement about what is actually the case. On the other hand, in 'He suggested that John take subj $_{\text {an }}$ aspirin', the complement sentence is in the subjunctive mood, as it describes a hypothetical situation in which John 
takes an aspirin, rather than an actual one. Colloquial English typically uses the indicative mood for both types of statements; other languages are stricter in grammatically marking this distinction and do so across a wide range of linguistic constructions.

Kovacic et al. (2016) propose that speakers of languages where irrealis mood, encoding non-factuality, is more pervasive perceive the world as more uncertain. They show a correlation between the intensity of use of irrealis mood in a language and risk perceptions of speakers of the language. Furthermore, they use mood as an instrument to study the effect of risk aversion on the probability of holding risky financial assets. In a further study, Kovacic and Orso (2016) demonstrate significantly higher intolerance towards immigration among individuals who speak a language where irrealis mood is used more frequently.

\section{Data}

\subsection{Data on Linguistic Structures}

The WALS (Dryer and Haspelmath, 2013) has served as the main source of data on linguistic structures in the literature surveyed in this paper. WALS is a large database of linguistic structures compiled by a team of 55 authors from published materials and other sources of cross-linguistic data. Substantive linguistic features (e.g. particular words or cognate sounds) are excluded from WALS. Instead it covers structural features, that is, 'abstract features of the language system that can be compared across unrelated languages' (Comrie et al., 2013). WALS contains information on 144 structural linguistic features.

On average, information for around 400 languages is presented for each linguistic feature, which is 'less than 10 percent of the world's languages, so the picture that we see in this atlas is far from complete' (Comrie et al., 2013). The language sample over which the data has been collected varies for different linguistic features. According to Comrie et al. (2013), there are 180 languages which appear under at least 80 linguistic features, and 449 languages which appear under at least 40 linguistic features. The choice of languages under each linguistic feature reflected the choice of individual authors who were guided with the principle of maximizing the 'genealogical and areal diversity' (Comrie et al., 2013). ${ }^{15}$ What this means is that information on key global languages (e.g. Hindi, Mandarin, Russian) is at times omitted. Moreover, the samples are often small relative to other sources of language information. For example, the Afrobarometer includes information on 466 different languages spoken at home, and while WALS has information on grammatical gender for 452 languages, the intersection of these is 19 languages only; this sharply limits the analysis of gendered language in Africa. ${ }^{16}$

Other cross-linguistic sources have been employed by studies either to complement the missing information in WALS (e.g. Mavisakalyan, 2015) or as a more substantial source in themselves (e.g. Chen, 2013). Examples include Dahl and Dienes (1984); Dahl (1985, 2000); Kashima and Kashima (1998, 2005); Bybee et al. (1994); Nurse (2008); Cyffer et al. (2009). Combining various sources does not appear to be a trivial task, however, since it may require ensuring compatibility across various concepts and definitions which may require specialized knowledge. One such attempt has been undertaken by Chen (2013), whose study is accompanied by a detailed appendix to present information on the way the languages have been used through consultation of multiple linguistic sources.

Another challenge is how best to operationalize the raw data on linguistic structures for use in economic analyses. Studies have often simply used existing information from WALS without thoroughly engaging with their relevance (e.g. Santacreu-Vasut et al., 2013; Hicks et al., 2015). Furthermore, some of the categorizations of complex linguistic structures into broad groupings might conceal information about different relevant aspects of languages. In addition, many differences between languages are also likely to be non-linear. Our impression is that more effort needs to go into both providing a careful account of the heterogeneity of languages across categories as well as generating valid aggregate variables based on individual linguistic features including issues of functional form, technique, etc.; for a good example of 
a nuanced approach to constructing linguistic variables see Davis and Abdurazokzoda (2016) treatment of pronominal expression and politeness distinctions.

\subsection{Data on Language Shares}

In cross-country regressions, the relevant linguistic structures are those that correspond to a country's most widely spoken language (e.g. Licht et al., 2007; Santacreu-Vasut et al., 2013; Bhalotra et al., 2015), or, to account for the heterogeneity in multilingual countries, it is taken as a weighted measure with weights given by the share of the population speaking each language (e.g. Tabellini, 2008; Chen, 2013; Mavisakalyan, 2015). Commonly used sources of data on language shares within countries include the World Factbook produced by the Central Intelligence Agency (2016) (which, however, often lists official languages rather than the shares of each language spoken in a country) and the Ethnologue project (Simons and Fennig, 2017) which lists over 7000 languages. Another possible source of data on language shares is Encyclopedia Britannica (2010) which reports the shares of languages spoken as 'mother tongues' generally based on national census data. ${ }^{17}$

At the individual level, linguistic structures (and the corresponding linguistic features) are linked to the language spoken at home. This data are available in various multi-country collections of nationally representative, individual-level surveys such as the World Values Surveys and Afrobarometer, or singlecountry representative individual-level surveys such as the General Social Survey and the American Community Surveys. In the absence of data on the language spoken at home, studies have employed proxies for primary language, such as the interview language (e.g. Chen, 2013), or the dominant language of the country of ancestry (e.g. Hicks et al., 2015). Furthermore, the structure of the language in which information is elicited (e.g. in the survey) may matter in addition to the structure of the primary spoken language (Mavisakalyan, 2015).

\section{Issues of Identification}

The existing studies on linguistic structures and economic outcomes establish fascinating patterns that, if real, could have important implications for research and policy. Nevertheless, there are important reasons for questioning whether these relationships are causal.

First, it is not completely implausible that certain economic outcomes may themselves causally affect linguistic structures in some cases. Some promising arguments to exclude this possibility have been made; most notably, Tabellini (2008) points out: 'As a classic example of network externalities, language evolves slowly over time. Linguistic innovations are costly because until they are widely adopted communications is more difficult' (p. 273). In support of this, Roberts et al. (2015) show that future-time reference variable, in particular, is very stable over time. This suggests that causation is more likely to flow from linguistic structures to contemporary values and outcomes than vice versa. Nevertheless, similar arguments adapted to the context of study may support the drawing of causal inferences.

More important than this reverse causality problem, there is an issue of omitted variables. The reasons why certain countries and individuals possess languages with specific structures are not random: both linguistic structures and economic outcomes may be the product of deeper, unobserved factors. In the extreme, this would mean that the estimated effects in the existing studies are entirely spurious. To highlight this, Roberts and Winters (2013) demonstrate that the failure to deal with unobservables may yield implausible links between traits such as linguistic diversity and traffic accidents.

Establishing whether the observed outcomes are a genuine consequence of linguistic structures involves making a choice of an identification strategy in the spectrum ranging from modelling naturally occurring data of various forms to generating data via laboratory experiments. 
Cross-country data-based research design has been at the core of several key contributions of this literature (e.g. Chen, 2013; Mavisakalyan, 2015; Davis and Abdurazokzoda, 2016). These have illustrated interesting aggregate patterns between linguistic structures and economic outcomes. However, crosscountry design has provided the least convincing approaches to identification. A conventional way to deal with the problem of endogeneity in cross-country framework is to use an instrumental variable: a source of exogenous variation in endogenous variable. However finding valid instrumental variables for linguistic structures is very difficult; there have been some attempts to use instrumental variables but the exclusion restrictions have been problematic (e.g. Mavisakalyan, 2015; Davis and Abdurazokzoda, 2016). Short of exploiting valid instrumental variables, cross-country evidence inevitably captures the effect of other determinants of economic and social outcomes.

Comparison of individuals living in the same (multilingual) country makes it possible to separate the effect of linguistic structures from country-level unobserved heterogeneity. This clearly improves upon existing identification approaches in cross-country framework. A promising proposal is to exploit variations in languages spoken by immigrants with similar characteristics, living in the same host country and sharing the same ancestry, applying epidemiological approach (Gay et al., 2016). Studying the behaviour of second-generation rather than first-generation immigrants appears to be particularly appropriate because issues of disruption and selection due to migration are more attenuated (Galor et al., 2016). While these identification approaches are clearly superior to cross-country analyses, making a fully convincing case for entirely random variation in linguistic structures in observational studies is a challenging task. This has motivated the introduction of experimental approaches in recent studies.

Experiments - natural or laboratory based - are a potentially promising approach to identifying the effect of linguistic structures. Natural experiments may involve, for example, changes from one language to another where the two differ in structure (Chen et al., 2015; Su et al., 2016), or potentially, structural changes within a single language. These are typically analysed within a difference-in-difference framework. The validity of this approach rests on the assumption that there are no time-varying shocks to the outcome variable that are correlated with the treatment variable. Defending this assumption appears to be crucial. Laboratory experiments can potentially provide an 'uncompromising glimpse' at the effects of exogenous treatments on behaviour in the lab (List, 2007). However, how much can be generalized based on experiments is a critical issue (for an insightful discussion on the generalizability of findings from laboratory experiments, see Levitt and List, 2007).

The rest of this section focuses on discussing specific proposals to mitigate the omitted variable bias.

\subsection{Cross-Country Comparisons}

A number of studies have investigated the association between linguistic structures and economic outcomes across countries. To mitigate the influence of unobserved heterogeneity, some studies have simply included controls for relevant observables while others have attempted instrumental variable estimations.

\subsubsection{Controlling for Unobserved Culture}

An important question in the literature is whether language acts as a mere marker of cultural values influencing economic outcomes. For example, formal systems of gender can be seen as indicative of a long history of gender distinction in given culture. If gendered language is correlated with more pronounced gender roles, then is it is due to the effect of language or whether gendered languages simply indicate the presence of cultural gender distinctions? To answer such questions, some studies have included different proxies for culture such as measures of attitudes and beliefs (e.g. Chen, 2013; Chen et al., 2015) and religious shares (e.g. Santacreu-Vasut et al., 2013; Gay et al., 2017). The results of these 
attempts show that the significant relationship between linguistic structures and outcomes persist after these variables are controlled for. However, clearly it is unlikely that these controls entirely capture all the relevant dimensions of culture. The question of whether linguistic structures simply proxy for culture therefore remains unresolved in these studies.

Resolving this question, however, appears to be essential to justify the uses of linguistic structures as instruments for cultures in cross-country studies of economic effects of cultures (e.g. Licht et al., 2007; Tabellini, 2008). The fact that linguistic structures do have a direct effect on economic outcomes after controlling for measures of culture throws into doubt the validity of such identification approaches and needs to be carefully considered in future research. The validity of these identification approaches would be threatened if there is indeed the possibility that linguistic structures may affect economic outcomes directly or through mechanisms other than culture, for example, institutions. Naturally, it is impossible to control for all possible variables that might be correlated with linguistic structures and economic outcomes in these studies. Overidentification tests are commonly used as a device to ascertain the exogeneity of instruments. However, such tests rely on finding additional instruments, of which at least one needs to be truly exogenous - a largely infeasible task in most practical contexts.

\subsubsection{Controlling for Other Confounders}

Existing attempts to isolate the economic effects of linguistic structures have also taken into account the relevance of historic origins of countries. These may potentially confound the relevant linguistic effects, as they may influence linguistic and cultural evolution. Indeed, as Galor et al. (2016) demonstrate, differences in pre-industrial geographical characteristics that were conducive to higher return to agricultural investment, larger gender gap in agricultural productivity, and more hierarchical society, have significant explanatory power over differences in the presence of the future tense, grammatical gender and politeness distinctions across languages. However, they are likely to also affect economic outcomes directly or via other mechanisms. To mitigate the effect of associated bias, cross-country studies have introduced some controls for confounding historical factors such as legal origins, colonization history, historical agricultural practices and language families (e.g. Chen et al., 2015; Roberts et al., 2015; Gay et al., 2017).

It is also possible that the linguistic structures of countries are spatially correlated, that is, that there is a concentration of certain linguistic structures in certain areas. If so, the effects attributed to language may be due to correlated geographical and climatic factors. To address this concern, cross-country studies have included continent fixed effects, and various other location and climatic controls such as the distance from the equator, the share of tropical population, the average number of frost days per unit of population, the share of coastal population, landlocked country status, etc. (e.g. Chen, 2013; Bhalotra et al., 2015; Mavisakalyan, 2015). To accurately address the issue of historical cultural transmissions across countries, Roberts et al. (2015) control for linguistic areas where linguistic contact is known to have historically occurred.

Finally, some studies have used falsification tests to gauge the likelihood of the established associations between linguistic structures and economic outcomes being spurious. These have involved controlling for additional linguistic structures theoretically irrelevant to outcomes of studies, to ascertain that an effect does not exist when it should not exist (e.g. Hicks et al., 2015; Mavisakalyan, 2015). While the falsification tests in these studies have been rejected, this does not in itself show that the primary associations of interest are causal.

\subsubsection{Instrumental Variable Regressions}

In most cross-country studies, the effects of linguistic structures persist once proxies for unobserved heterogeneity are included. ${ }^{18}$ Still, unobserved heterogeneity can never be exhaustively controlled for. In 
cross-country analysis there are several important challenges concerning (i.) unavailability of information on many relevant omitted variables; (ii.) lack of independent variation in linguistic structures and its correlates that may also affect the outcome of interest; and (iii.) exhaustion of the available degrees of freedom in regressions where countries are observations.

A conventional way to directly address the problem of endogeneity is to use an instrumental variable. In practice, however, finding a persuasive instrument for linguistic structures is extremely hard. Two main attempts to establish a causal effect of linguistic structures through the use of instrumental variables have emerged in the cross-country literature. Davis and Abdurazokzoda (2016) use the grammatical rules of related languages to establish a causal link from the linguistic structures of a country's dominant language to its culture. ${ }^{19}$ Mavisakalyan (2015) presents another attempt to identify the effect of language by using language families as instruments for linguistic structures. These approaches assume that the horizontal or vertical relatedness of languages is not correlated with unobserved determinants of outcomes studied. Mavisakalyan (2015) acknowledges the limitations of the identification strategy in her study by noting that '...the linguistic trees may be related to pre-historic migration movements, which may have taken place due to particular economic reasons affecting gender differences in labour force participation' (p. 410), that is, the outcome variable of interest.

\subsection{Within-Country Comparisons}

So far, the economics literature on linguistic structures contains two main approaches to studying individuals in the same country. The first directly builds on the design used in cross-country comparisons and estimates country fixed effects models exploiting the presence of multilingual countries with sufficient linguistic diversity to allow for within-country comparisons, in addition to cross-country comparisons (based on the World Values Surveys, for example) (e.g. Chen, 2013; Mavisakalyan, 2015). ${ }^{20}$ These approaches effectively compare the outcomes of observationally identical individuals (controlling for wide range of characteristics capturing individuals' demographic and socio-economic standing but also some values and beliefs) living in the same country that speak languages with different linguistic structures. By fully accounting for unobserved heterogeneity at the country level, this approach is better suited to identify the causal effect of languages than cross-country studies.

Typically, immigrants are excluded from these analyses '...so as to avoid conflating differences in a household's primary language with differences between natives and immigrants' (Chen, 2013, p. 700). In practice, however, it is likely that a lot of the within-country variation in spoken languages comes from second- or higher generation immigrants. If so, not only does the approach of excluding firstgeneration immigrants not entirely deal with this difficulty, it is also problematic due to its failure to identify differences in the type of ancestry (different higher order immigrants, indigenous populations, etc.), generation of residence (some may have been in the country for many generations whereas other may be second generation), etc. which may have important implications for the study of the effects of linguistic structures.

The second approach to within-country comparisons, on the other hand, specifically targets the behaviour of first- (e.g. Hicks et al., 2015; Gay et al., 2017) or second-generation (e.g. Galor et al., 2016) immigrants, and applies an epidemiological approach to separate the effect of language from country-level unobserved heterogeneity. This approach rests on 'exploiting the differential portability of culture relative to markets and institutions' (Fernandez, 2007, p. 310) and was first introduced for studying the effect of culture on economic outcomes (see, e.g. Fernandez, 2008, for an overview). Gay et al. (2016) provide a discussion on the relevance of studying immigrant populations for gaining insights into the relationship between linguistic structures and economic outcomes.

Like the approach of none-immigrants studies discussed above, the epidemiological approach is based on the comparison of outcomes of observationally identical individuals in the same country who speak 
languages with different linguistic structures. In contrast to traditional epidemiological approaches, however, the version adopted by studies of linguistic structures also accounts for individuals' countriesof-ancestry (e.g. Galor et al., 2016; Gay et al., 2017). Hence, in effect, the analysis is based on exploiting variations of languages spoken by individuals with similar characteristics, living in the same place and sharing the same ancestry. This approach effectively helps to overcome potential biases generated by omitted ancestral characteristics not accounted for in previous studies.

Nevertheless, some of the epidemiological approaches to within-country comparisons of linguistic structures have their own drawbacks. In particular, studies of first generation immigrants are likely to be problematic (e.g. Hicks et al., 2015; Gay et al., 2017). Recent immigrants may face shocks (e.g. on language, culture) which can affect their usual behaviours. Further, recent immigrants are unlikely to be a representative sample of home-country populations; in particular, their linguistic and cultural profile is likely to be different from home country averages. These issues are largely mitigated when studying the behaviour of second-generation immigrants Galor et al. (2016). Finally, the issue of why we observe variation across languages within countries and ancestries and whether such variation is random remains to be comprehensively accounted for. ${ }^{21}$

\subsection{Experiments}

A promising way to identify the effects of linguistic structures is to study natural experiments involving changes of languages with different structures or changes within a language. An exogenous change from a language with one structure to a language with another structure within a country has recently been exploited for the study of tense. Chen et al. (2015) and Su et al. (2016) provide difference-in-differences analyses based on the case of Hong Kong, where a weak-FTR language (Chinese) relative to a strong-FTR language (English) became increasingly important after the 1997 transfer of sovereignty from the United Kingdom to China. They use this natural experiment to examine the effect of an increased significance of a weak-FTR language on cash holdings (Chen et al., 2015) and investment in research and development (Su et al., 2016) in Hong Kong firms, compared to several control groups. Similar evidence for other contexts would be useful.

In addition, the effect of languages has been studied in a controlled laboratory experimental setting. A study by Sutter et al. (2015) presents the pioneering contribution to this strand by providing evidence on intertemporal choices of strong-FTR (Italian) and weak-FTR (German) speaking children in a bilingual city in northern Italian. The study is based on a controlled and incentivized experiment in which the authors directly elicit intertemporal preferences, thus keeping the environment as identical as possible for members of the two language groups. While this approach potentially allows for causal interpretation, a major drawback is the loss of external validity.

\section{Conclusion}

Linguistic structures are emerging as an important determinant of a wide range of economic behaviours and outcomes. The nascent economics literature surveyed in this paper has uncovered fascinating effects of linguistic structures. Nonetheless, there is work to be done.

We need to pay careful attention to the measurement of linguistic structures that are theoretically relevant and accurately reflect the complexity in which grammars differ. This may also assist in uncovering the mechanism by which given effects are mediated. Collaborations with linguists can help to achieve higher accuracy in measurement tasks.

Further, we need to improve our understanding of the causal relationship between linguistic structures and economic outcomes. There is a growing body of experimental evidence on this issue, which is, however, weak on external validity. Natural experiments of language changes within a country offer 
promising opportunities for causal identification. Also, investigating changes within a language (e.g. loss of the distinction between the formal and informal 'you' in the Scandinavian languages and English) are another promising area of future research aimed at establishing causality.

While the existing studies provide initial evidence on the economic effects of four linguistic structures (i.e. gender, tense, pronouns, mood), there are numerous linguistic structures yet to be considered that may likely also reveal differences in outcomes. Some promising candidates are, for instance, the potential effect of word order, possessive constructions and use of agentive versus non-agentive verbs. Future research may also explore new areas where the linguistic structures already considered may have additional effects.

The results of the literature may play an important role in policy making. As this survey indicates, linguistic structures have both costs and benefits. When they are advantageous for certain desired outcomes (e.g. absence of future tense promoting pro-saving behaviour), this should add to the economic benefits of language learning, in addition to its direct labour market value. On the other hand, the economic costs of certain linguistic structures (e.g. gender marking affecting women's employment) should also be considered in policy making.

Indeed, the fact that language structures may have important socioeconomic consequences has been at the core of several language reform proposals. In the case of gender, for example, the promotion of new gender-neutral terms and ways of communicating has been pursued by the Swedish Language Council (Milles, 2011). There have even been proposals by some feminists to introduce a new genderless language as a path towards gender equality (e.g. Elgin, 1985). Such reforms, if executed, are very costly. The results from the new literature on linguistic structures and economics can form a vital source of evidence for such interventions.

\section{Notes}

1. Data on the relationships among languages offer further opportunities to expand the boundaries of economic analyses; for example, measures of linguistic distance based on shared structural (Fearon, 2003; Spolaore and Wacziarg, 2009) and phonetic (Isphording and Otten, 2013, 2014; Isphording, 2014) features introduced by recent studies.

2. Thus, we endorse an internal, that is, psychological, interpretation of culture, in contrast to an external, that is, non-psychological, view Prinz (2016). Understanding culture internally, in terms of information and ideas, is also standard practice in biological anthropology. For instance, Richerson and Boyd (2005, p. 5) define culture as 'information capable of affecting individuals' behaviour that they acquire from other members of their species [...]'. Likewise, Dawkins (1976) explains culture in terms of 'memes', that is, mental representations of ideas, habits, norms and other items of cultural transmission.

3. Like all definitions of culture in economics, this is a somewhat technical notion, both narrower and wider than our everyday concept.

4. We will see that adequately modelling the influence of language on behaviour may require a moderate expansion of the standard decision theoretic framework-language may affect the partitioning of an agent's possibility space $\Omega$ and the salience of partition cells. This explains the modified cognition box in Figure 1(b).

5. For a detailed history, see Aarsleff (1988) and Koerner (1992).

6. There is some evidence supporting strong versions of the LRH, for example, linking number concepts and number cognition (Frank et al., 2008).

7. The Chomskian paradigm is not uncontested, see, for example, Evans and Levinson (2009) for opposition.

8. For instance, Scholz et al. (2016) write, 'there is no clear conflict or even a conceptual connection between Whorf's views about language placing limits on developmental plasticity, and Chomsky's thesis of an innate universal architecture for syntax'. 
9. The classical formulations of decision theory are due to Leonard Savage (1954) and Richard Jeffrey (1965). For non-standard versions of decision theory see, for example, Weirich (2004) and Bradley (2017).

10. Some doubt whether the influence of certain cultural items, in particular sociocultural norms, can be understood in the orthodox decision theoretic framework. However, Broome (1992) has shown that we can indeed accommodate norms within this framework by incorporating the fact that a norm has been obeyed/violated into the representation of an action's outcomes, to which an agent's utility function may then be sensitive.

11. We also find combinations of (1)-(4), for example, grammatical tense and gender seem to operate through multiple channels.

12. We're not suggesting that the relevant distinctions are entirely unavailable for certain speakers. In practice, it may be enough if language affects the ease or speed in which certain distinctions can be drawn.

13. Under this category, one might also subsume influences through habituation (Majid, 2002) and other effects on reasoning processes, that is, certain linguistic features may simplify cognitive processes relevant for practical deliberation.

14. Some studies have additionally considered two alternative continuous measures of language FTR: verb ratio and sentence ratio, defined as the frequency of verbs and sentences respectively that are grammatically future-marked in weather forecasts (e.g. Chen, 2013; Paule-Paludkiewicz et al., 2016; Su et al., 2016).

15. In the genealogical classification of languages, a genus is a group of languages whose relatedness is fairly obvious without systematic comparative analysis (Dryer, 2013). Information on the genealogical classification of languages, particularly at the highest level, that of language families, as well as on various intermediate groupings is available in WALS.

16. We thank an anonymous referee for this example.

17. Mavisakalyan (2015) uses the secondary version of this data originally compiled by Alesina et al. (2003).

18. One exception is the study by Roberts et al. (2015), based on mixed-method modelling approaches, which shows that cross-country effects of languages are not always robust when historical and geographic relatedness of languages is accounted for.

19. For each language, they compute a weighted average of the linguistic rules of all of the other languages in the sample where the weights are proportional to the linguistic proximity of the languages.

20. Studies based on cases of single multilingual countries such as Belgium ( $\mathrm{Su}$ et al., 2016), Canada (Chen et al., 2015) and Switzerland (Chen et al., 2015; Guin, 2015) have also recently emerged in the literature. By estimating language effects at smaller geographic scope, these approaches potentially allow to control more extensively for unobserved heterogeneity.

21. For example, it is possible that within-country-of-ancestry variation reflects socioeconomic status (e.g. use of Russian versus local language among immigrants from certain post-Soviet states; use of French versus Arabic among immigrants from certain post-colonial countries in the Middle East). Some of these concerns can be effectively eliminated by inclusion of controls, for example, Galor et al. (2016) control for parents' human capital.

\section{References}

Aarsleff, H. (1988) Introduction. On Language. Wilhelm von Humboldt. Translated by Peter Heath. Cambridge: Cambridge University Press.

Alesina, A., Devleeschauwer, A., Easterly, W., Kurlat, S. and Wacziarg, R. (2003) Fractionalization. Journal of Economic Growth 8(2): 155-194.

Alesina, A. and Giuliano, P. (2007) The power of the family. IZA Discussion Paper 2750. 
Alesina, A. and Giuliano, P. (2015) Culture and institutions. Journal of Economic Literature 53(4): 898-944.

Alesina, A., Giuliano, P. and Nunn, N. (2013) On the origins of gender roles: Women and the plough. The Quarterly Journal of Economics 128(2): 469-530.

Becker, A., Dohmen, T.J., Enke, B., Falk, A., Huffman, D., Sunde, U. et al. (2015) The nature and predictive power of preferences: Global evidence. CEPR Discussion Papers.

Bhalotra, S., Clarke, D., Gomes, J. and Venkataramani, A. (2015) Maternal mortality and female life expectancy: The importance of gender inequality. Unpublished manuscript.

Boroditsky, L. (2003) Linguistic relativity. In L. Nadel (ed.), Encyclopedia of Cognitive Science (pp. 917-921). London, UK: MacMillan Press.

Boroditsky, L., Schmidt, L.A. and Phillips, W. (2003) Sex, syntax, and semantics. In D. Gentner and S. Goldin-Meadow (eds.), Language in Mind: Advances in the Study of Language and Thought (pp. 61-79). Cambridge, Massachusetts: The MIT Press.

Bradley, R. (2017) Decision Theory with a Human Face. Cambridge: Cambridge University Press.

Broome, J.R. (1992) Deontology and economics. Economics and Philosophy 8: 269-282.

Bybee, J.L., Perkins, R.D. and Pagliuca, W. (1994) The Evolution of Grammar: Tense, Aspect, and Modality in the Languages of the World. Chicago, Illinois: University of Chicago Press Chicago.

Casasanto, D. (2010) Space for thinking. In V. Evans and P. Chilton (eds.), Language, Cognition and Space: The State of the Art and New Directions (pp. 453-478). London, UK: Equinox Publishing.

Casasanto, D. (2015) Linguistic relativity. In N. Riemer (ed.), Routledge Handbook of Semantics (pp. 158-174). New York: Routledge.

Casasanto, D. (2016) A shared mechanism of linguistic, cultural, and bodily relativity. Language Learning 66(3): 714-730.

Casasanto, D. and Boroditsky, L. (2008) Time in the mind: Using space to think about time. Cognition 106(2): 579-593.

Central Intelligence Agency (2016) The World Factbook. Washington, DC. Available at: https://www.cia.gov/library/publications/the-world-factbook/index.html.

Chen, M.K. (2013) The effect of language on economic behavior: Evidence from savings rates, health behaviors, and retirement assets. The American Economic Review 103(2): 690-731.

Chen, S., Cronqvist, H., Ni, S. and Zhang, F. (2015) Languages and corporate cash holdings: International evidence. Technical report, China Europe International Business School.

Chierchia, G. (1999) Linguistics and language. In R.A. Wilson and F.C. Keil (eds.), The MIT Encyclopedia of the Cognitive Sciences (pp. xci-cix). Cambridge, Massachusetts: MIT Press.

Chiswick, B.R. and Miller, P.W. (2015) International migration and the economics of language. In B. Chiswick and P. Miller (eds.), Handbook of the Economics of Immigration (pp. 211-269). Amsterdam, The Netherlands: Elsevier.

Chomsky, N. (1957) Syntactic Structures. The Hague: Mouton.

Comrie, B., Dryer, M.S., Gil, D., and Haspelmath, M. (2013) Introduction. Leipzig: Max Planck Institute for Evolutionary Anthropology.

Corbett, G. (1991) Gender. Cambridge Textbooks in Linguistics. Cambridge, UK: Cambridge University Press.

Corbett, G.G. (2013a) Number of Genders. Leipzig: Max Planck Institute for Evolutionary Anthropology.

Corbett, G.G. (2013b) Systems of Gender Assignment. Leipzig: Max Planck Institute for Evolutionary Anthropology.

Cyffer, N., Ebermann, E. and Ziegelmeyer, G. (2009) Negation Patterns in West African Languages and Beyond. Amsterdam, The Netherlands: John Benjamins Publishing.

Dahl, Ö. (1985) Tense and aspect systems. Oxford, UK: Basil Blackwell.

Dahl, Ö. (2000) The grammar of future time reference in European languages. In Ö. Dahl (ed.), Tense and Aspect in the Languages of Europe. Berlin: Mouton de Gruyter.

Dahl, O. and Dienes, D.K. (1984) Selected Working Papers from the Tense-Mood-Aspect Project. Institute of Linguistics, University of Stockholm.

Davis, L. and Reynolds, M. (2016) Gendered language and the educational gender gap. Available at SSRN: https://ssrn.com/abstract=2782540 (Accessed on 07/02/2017).

Davis, L.S. and Abdurazokzoda, F. (2016) Language, culture and institutions: Evidence from a new linguistic dataset. Journal of Comparative Economics 44(3): 541-561. 
Davis, L.S. and Williamson, C.R. (2016) Culture and the regulation of entry. Journal of Comparative Economics 44(4): 1055-1083.

Dawkins, R. (1976) The Selfish Gene. New York: Oxford University Press.

Di Paolo, A. and Tansel, A. (2015) Returns to foreign language skills in a developing country: The case of turkey. The Journal of Development Studies 51(4): 407-421.

Dryer, M.S. (2013) Genealogical Language List. Leipzig: Max Planck Institute for Evolutionary Anthropology.

Dryer, M.S. and Haspelmath, M. (eds.) (2013) WALS Online. Leipzig: Max Planck Institute for Evolutionary Anthropology.

Duncan, A. and Mavisakalyan, A. (2015) Russian language skills and employment in the Former Soviet Union. Economics of Transition 23(3): 625-656.

Elgin, S.H. (1985) A First Dictionary and Grammar of Laadan. Madison, WI: Society for the Furtherance and Study of Fantasy and Science Fiction.

Encyclopedia Britannica (2010) Encyclopedia Britannica. Chicago, Illinois.

Evans, N. and Levinson, S.C. (2009) The myth of language universals: Language diversity and its importance for cognitive science. Behavioral and Brain Dciences 32(05): 429-448.

Fasan, M., Gotti, G., Kang, T. and Liu, Y. (2016) Language FTR and earnings management: International evidence. Available at SSRN 2763922.

Fausey, C.M. and Boroditsky, L. (2010) Subtle linguistic cues influence perceived blame and financial liability. Psychonomic Bulletin \& Review 17(5): 644-650.

Fausey, C.M. and Boroditsky, L. (2011) Who dunnit? Cross-linguistic differences in eye-witness memory. Psychonomic Bulletin \& Review 18(1): 150-157.

Fearon, J.D. (2003, Jun) Ethnic and cultural diversity by country. Journal of Economic Growth 8(2): 195-222.

Fernandez, R. (2007) Alfred marshall lecture women, work, and culture. Journal of the European Economic Association 5(2-3): 305-332.

Fernandez, R. (2008) Culture and economics. In S.N. Durlauf and L.E. Blume (eds.), The New Palgrave Dictionary of Economics (pp.1229-1236). Basingstoke: Palgrave Macmillan.

Fernandez, R. and Fogli, A. (2006) Fertility: The role of culture and family experience. Journal of the European Economic Association 4(2-3): 552-561.

Fernandez, R. and Fogli, A. (2009) Culture: An empirical investigation of beliefs, work, and fertility. American Economic Journal: Macroeconomics 1(1): 146-177.

Fidrmuc, J. and Fidrmuc, J. (2016) Foreign languages and trade: Evidence from a natural experiment. Empirical Economics 50(1): 31-49.

Figlio, D., Giuliano, P., Özek, U. and Sapienza, P. (2016) Long-term orientation and educational performance. NBER Working Paper Series (22541).

Fodor, J.A. (1983) The Modularity of Mind: An Essay on Faculty Psychology. Cambridge, Massachusetts: MIT Press.

Frank, M.C., Everett, D.L., Fedorenko, E. and Gibson, E. (2008) Number as a cognitive technology: Evidence from Pirahã language and cognition. Cognition 103(8): 819-824.

Galor, O., Özak, Ö. and Sarid, A. (2016) Geographical origins and economic consequences of language structures. Unpublished manuscript.

Gay, V., Hicks, D.L. and Santacreu-Vasut, E. (2016) Migration as a window into the coevolution between language and behavior. Available at SSRN 2747153.

Gay, V., Hicks, D.L., Santacreu-Vasut, E. and Shoham, A. (2017) Decomposing culture: An analysis of gender, language, and labor supply in the household. Review of Economics of the Household. https://doi.org/10.1007/s11150-017-9369-x

Gentner, D. and Goldin-Meadow, S. (2003) Language in Mind: Advances in the Study of Language and Thought. Cambridge: MIT press.

Givati, Y. and Troiano, U. (2012) Law, economics, and culture: Theory of mandated benefits and evidence from maternity leave policies. Journal of Law and Economics 55(2): 339-364.

Gleitman, L. and Papafragou, A. (2013) Relations between language and thought. In D. Reisberg (Ed.), Handbook of Cognitive Psychology (pp. 504-523). Oxford, UK: Oxford University Press.

Gorodnichenko, Y. and Roland, G. (2017) Culture, institutions, and the wealth of nations. The Review of Economics and Statistics 99(3): 402-416. 
Guin, B. (2015) Culture and household saving. Available at SSRN 2698872.

Guiso, L., Sapienza, P., and Zingales, L. (2006) Does culture affect economic outcomes? The Journal of Economic Perspectives 20(2): 23-48.

Gumperz, J.J. and Levinson, S. (1996) Rethinking linguistic relativity, Volume 17 ofStudies in the Social and Cultural Foundations of Language. Cambridge: Cambridge University Press.

Henrich, J., Boyd, R., Bowles, S., Camerer, C., Fehr, E., Gintis, H. and McElreath, R. (2001) In search of homo economicus: Behavioral experiments in 15 small-scale societies. The American Economic Review 91(2): 73-78.

Hicks, D.L., Hicks, J.H. and Maldonado, B. (2016) Women as policy makers and donors: Female legislators and foreign aid. European Journal of Political Economy 41: 46-60.

Hicks, D.L., Santacreu-Vasut, E. and Shoham, A. (2015) Does mother tongue make for women's work? Linguistics, household labor, and gender identity. Journal of Economic Behavior and Organization 110: $19-44$.

Hübner, M. and Vannoorenberghe, G. (2015a) Patience and inflation. MPRA Paper (65811).

Hübner, M. and Vannoorenberghe, G. (2015b) Patience and long-run growth. Economics Letters 137: $163-167$.

Isphording, I.E. (2014) Disadvantages of linguistic origin: Evidence from immigrant literacy scores. Economics Letters 123(2): 236-239.

Isphording, I.E. and Otten, S. (2013) The costs of Babylon? Linguistic distance in applied economics. Review of International Economics 21(2): 354-369.

Isphording, I.E. and Otten, S. (2014) Linguistic barriers in the destination language acquisition of immigrants. Journal of Economic Behavior \& Organization 105: 30-50.

Jeffrey, R.C. (1965) The Logic of Decision. Chicago, Illinois: University of Chicago Press.

Kashima, E.S. and Kashima, Y. (1998) Culture and language: The case of cultural dimensions and personal pronoun use. Journal of Cross-Cultural Psychology 29(3): 461-486.

Kashima, E.S. and Kashima, Y. (2005) Erratum to Kashima and Kashima (1998) and reiteration. Journal of Cross-Cultural Psychology 36(3): 396-400.

Kay, P. and Regier, T. (2006) Language, thought and color: Recent developments. Trends in Cognitive Sciences 10(2): 51-54.

Koerner, E. (1992) The Sapir-Whorf hypothesis: A preliminary history and a bibliographical essay. Journal of Linguistic Anthropology 2(2): 173-198.

Kovacic, M., Costantini, F., and Bernhofer, J. (2016) Risk attitudes, investment behavior and linguistic variation. University Ca'Foscari of Venice, Dept. of Economics Research Paper Series No 34/WP/2015.

Kovacic, M. and Orso, C.E. (2016) Why do some countries fear immigration more than others? Evidence from Europe. University Ca'Foscari of Venice, Dept. of Economics Research Paper Series No 05/WP/2016.

Lazear, E.P. (1999) Culture and language. Journal of Political Economy 107(S6): S95-S126.

Levinson, S.C. (2003) Language and mind: Let's get the issues straight. In D. Gentner and S. Goldin-Meadow (eds.), Language in Mind: Advances in the Study of Language and Thought (pp. 25-46). Cambridge, Massachusetts: MIT Press.

Levinson, S.C. and Wilkins, D.P. (2006) Grammars of Space: Explorations in Cognitive Diversity, Volume 6. Cambridge, UK: Cambridge University Press.

Levitt, S.D. and List, J.A. (2007) What do laboratory experiments measuring social preferences reveal about the real world? The Journal of Economic Perspectives 21(2): 153-174.

Liang, H., Marquis, C., Renneboog, L. and Sun, S.L. (2014) Speaking of corporate social responsibility. Harvard Business School Organizational Behavior Unit Working Paper (14-082).

Licht, A.N., Goldschmidt, C. and Schwartz, S.H. (2007) Culture rules: The foundations of the rule of law and other norms of governance. Journal of Comparative Economics 35(4): 659-688.

List, J.A. (2007) Field experiments: A bridge between lab and naturally occurring data. The BE Journal of Economic Analysis \& Policy 5(2): 1-47.

Lucy, J.A. (1992) Language Diversity and Thought: A Reformulation of the Linguistic Relativity Hypothesis. Cambridge, UK: Cambridge University Press.

Lucy, J.A. (1996a) Grammatical Categories and Cognition: A Case Study of the Linguistic Relativity Hypothesis. Cambridge, UK: Cambridge University Press. 
Lucy, J.A. (1996b) Language diversity and thought: A reformulation of the linguistic relativity hypothesis. In J.J. Gumperz and S.C. Levinson (eds.), Rethinking linguistic relativity, Volume 17 of Studies in the Social and Cultural Foundations of Language (pp. 37-61). Cambridge: Cambridge University Press.

Lucy, J.A. (1997) Linguistic relativity. Annual Review of Anthropology 26: 291-312.

Majid, A. (2002) Frames of reference and language concepts. Trends in cognitive sciences 6(12): 503-504.

Marschak, J. (1965) Economics of language. Behavioral Science 10(2): 135-140.

Mavisakalyan, A. (2015) Gender in language and gender in employment. Oxford Development Studies 43(4): 403-424.

Melitz, J. (2008) Language and foreign trade. European Economic Review 52(4): 667-699.

Milles, K. (2011) Feminist language planning in Sweden. Current Issues in Language Planning 12(1): 21-33.

Nurse, D. (2008) Tense and Aspect in Bantu. New York: Oxford University Press.

Oh, K.J. (2003) Language, Cognition, and Development: Motion Events in English and Korean. Ph. D. thesis, University of California, Berkeley.

Pascual-Ezama, D., Fosgaard, T.R., Cardenas, J.C., Kujal, P., Veszteg, R., de Liano, B.G.-G., Gunia, B., Weichselbaumer, D., Hilken, K., Antinyan, A., Delnoij, J., Proestakis, A., Tira, M.D., Pratomo, Y., Jaber-Lopez, T. and Branas-Garza, P. (2015) Context-dependent cheating: Experimental evidence from 16 countries. Journal of Economic Behavior \& Organization 116: 379-386.

Paule-Paludkiewicz, H., Fuchs-Schündeln, N. and Masella, P. (2016) Cultural determinants of household saving behavior. Beiträge zur Jahrestagung des Vereins für Socialpolitik 2016: Demographischer Wandel - Session: Saving, Wealth and Retirement (F07-V1).

Perez, E.O. and Tavits, M. (2016) Language shapes public attitudes toward gender equality. Unpublished manuscript.

Pinker, S. (1994) The Language Instinct: How the Mind Creates Language. New York: Harper.

Prinz, J. (2016) Culture and cognitive science. In E.N. Zalta (Ed.), The Stanford Encyclopedia of Philosophy. Metaphysics Research Lab, Stanford University. https://plato.stanford.edu/ archives/fall2016/entries/culture-cogsci/

Regier, T. and Kay, P. (2009) Language, thought, and color: Whorf was half right. Trends in cognitive sciences 13(10): 439-446.

Richerson, P.J. and Boyd, R. (2005) Not by Genes Alone. Chicago: University of Chicago Press.

Roberts, S. and Winters, J. (2013, 08) Linguistic diversity and traffic accidents: Lessons from statistical studies of cultural traits. PLoS One 8(8): 1-13.

Roberts, S.G., Winters, J. and Chen, K. $(2015,07)$ Future tense and economic decisions: Controlling for cultural evolution. PLoS One 10(7): 1-46.

Santacreu-Vasut, E., Shenkar, O. and Shoham, A. (2014) Linguistic gender marking and its IB ramifications. Journal of International Business Studies 45(9): 1170-1178.

Santacreu-Vasut, E., Shoham, A., and Gay, V. (2013) Do female/male distinctions in language matter? Evidence from gender political quotas. Applied Economics Letters 20(5): 495-498.

Sapir, E. (1929) The status of linguistics as a science. Language 5: 207-214.

Saul, J. (2012) Feminist philosophy of language. In E.N. Zalta (Ed.), The Stanford Encyclopedia of Philosophy (Winter 2012 ed.). https://plato.stanford.edu/archives/fall2017/entries/feminism-language

Savage, L.J. (1954) The foundations of Statistics. Oxford, UK: John Wiley and Sons.

Scholz, B.C., Pelletier, F.J. and Pullum, G.K. (2016) Philosophy of linguistics. In E.N. Zalta (Ed.), The Stanford Encyclopedia of Philosophy (Winter 2016 ed.) Metaphysics Research Lab, Stanford University. https://plato.stanford.edu/archives/win2016/entries/linguistics

Simons, G.F. and Fennig, C.D. (eds.) (2017) Ethnologue: Languages of the World. Dallas, TX: SIL International. Online version: http://www.ethnologue.com.

Slobin, D.I. (2003) Language and thought online: Cognitive consequences of linguistic relativity. In D. Gentner and S. Goldin-Meadow (eds.), Language in Mind: Advances in the Study of Language and Thought (pp. 157-192). Cambridge, Massachusetts: The MIT Press.

Spolaore, E. and Wacziarg, R. (2009) The diffusion of development. The Quarterly Journal of Economics 124(2): 469-529.

Su, X., Tang, Y. and Xu, B. (2016) Reward-timing uncertainty, languages, and R\&D investment. Unpublished manuscript. 
Sutter, M., Angerer, S., Rützler, D. and Lergetporer, P. (2015) The effect of language on economic behavior: Experimental evidence from children's intertemporal choices. IZA Discussion Paper No. 9383.

Tabellini, G. (2008) Presidential address institutions and culture. Journal of the European Economic Association 6(2-3): 255-294.

Takano, Y. (1989) Methodological problems in cross-cultural studies of linguistic relativity. Cognition 31(2): $141-162$.

Tversky, A. and Kahneman, D. (1975) Judgment under uncertainty: Heuristics and biases. In D. Wendt (ed.), Utility, Probability, and Human Decision Making (pp. 141-162). Dordrecht, Netherlands: Springer.

van der Velde, L., Tyrowicz, J. and Siwinska, J. (2015) Language and (the estimates of) the gender wage gap. Economics Letters 136: 165-170.

Weirich, P. (2004) Realistic Decision Theory: Rules for Nonideal Agents in Nonideal Circumstances. New York: Oxford University Press.

Whorf, B.L. (1956) Language, Thought, and Reality: Selected Writings of Benjamin Lee Whorf. Cambridge, Massachusetts: MIT Press.

Winawer, J., Witthoft, N., Frank, M.C., Wu, L., Wade, A.R. and Boroditsky, L. (2007) Russian blues reveal effects of language on color discrimination. Proceedings of the National Academy of Sciences 114(19): $7780-7785$.

Yao, Y. and van Ours, J.C. (2015) Language skills and labor market performance of immigrants in the Netherlands. Labour Economics 34: 76-85. [European Association of Labour Economists 26th Annual Conference.] 